\title{
Sterically Stabilized Emulsion Polymerization of Styrene
}

\author{
Ignác CAPEK ${ }^{\dagger}$ \\ Polymer Institute, Slovak Academy of Sciences, 84236 Bratislava, Slovakia
}

(Received July 8, 2003; Accepted October 24, 2003)

\begin{abstract}
Batch emulsion polymerizations of styrene initiated by ammonium peroxodisulfate (APS) and 2,2'azobisizobutyronitrile (AIBN) at a broad monomer concentration range were investigated. The role of the thick emulsifier layer formed by a nonionic emulsifier was investigated in the sterically stabilized emulsion polymerization of styrene. The polymerization rate $v s$. conversion dependence was characterized by two or three nonstationary rate intervals. The rate of polymerization increases with the monomer concentration and the increase is much more pronounced at lower monomer concentrations. The deviation from the micellar model was ascribed to the high oil-solubility of nonionic emulsifier and the chain transfer and desorption events. The values of desorption rate constant $k_{\text {des }}^{\prime}$ for the sterically stabilized emulsion polymerization of styrene are slightly than those for the electrostatically stabilized emulsion polymerization of styrene. The number of polymer particles is nearly independent of the monomer concentration at $c a$. 20-30\% conversion. The dependence of the final polymer particle number vs. the monomer concentration is described by a curve with a maximum. The primary radical termination decreases the rate of polymerization, the number of polymer particles and the final conversion at the high concentration of both APS and AIBN. In the former APS system the less hydrophobic oligomeric radicals with depressed entry rate into particles appear. In the latter AIBN system the growing radicals are deactivated by primary radicals derived from AIBN. The similar polymerization behavior for both initiators results from the dominant chain transfer and radical exit events. The molecular weight of polystyrene is inversely proportional to the initiator concentration.

KEY WORDS Emulsion Polymerization / Styrene / Nonionic Emulsifier / Desorption of Radicals / Polymer Particles / Kinetic / Colloidal and Molecular Weight Parameters /
\end{abstract}

Non-ionic emulsifiers of the alkyl- or aryl-poly(oxyethylene) (PEO) type are very popular as emulsion stabilizers. They enhance the chemical and freeze-thaw stability of the latex products. The coarse polymer emulsions are formed by emulsion polymerization stabilized by nonionic emulsifier. ${ }^{1,2}$ The colloidal stability of polymer latex stabilized by the PEO nonionic emulsifier is nearly independent of electrolyte concentration but they are temperature-dependent. The extension of PEO chains into the aqueous phase decreases with increasing temperature.

The charged latex particles are stabilized via the electrostatic repulsion force between two approaching particles (the electrostatic stabilization). ${ }^{3,4}$ The electrostatic repulsion between particles is formed by electrical double layers that surround them when covering the particles with charged species, such as ionic emulsifiers. In the sterically stabilized particles the repulsion between particles is provided by steric repulsion between approaching particles. ${ }^{5,6}$ The thick interfacial layer formed by nonionic emulsifier may make a barrier for entering radicals and/or prolong the time interval between entries of two radicals.

The models developed for the electrostatically stabilized latex particles ${ }^{7}$ are only partially applicable when dealing with latexes stabilized by electrosteric

${ }^{\dagger}$ To whom correspondence should be addressed. or steric mechanism. For example, the electrosterically-stabilized latexes show somewhat smaller values of both entry $\left(k_{\mathrm{a}}\right)$ and exit $\left(k_{\mathrm{des}}\right)$ rate coefficients as compared to the electrostatically-stabilized latex particles of the same size. ${ }^{8-10}$ The decreased $k_{\mathrm{a}}$ or $k_{\mathrm{des}}$ in the sterically-stabilized latexes is ascribed to a "hairy" layer around the particles, which retards diffusion of oligomeric radicals. The entering radicals may be terminated prior to the actual entry into the latex particles occurs. However, there are no kinetic models for the sterically-stabilized latex particles.

In the previous works, ${ }^{11,12}$ we have studied the sterically stabilized microemulsion polymerization of styrene at different temperatures. The rates of particle formation and polymerization strongly increased with increasing temperature. The particle nucleation proceeded up to the high conversion and the increase in the particle size was more pronounced up to $c a$. $40 \%$ conversion. The major thrust of this work is to discuss the role of the thick interfacial layer formed by nonionic emulsifier. The thick emulsifier layer was formed by Tween 20 on the surface of monomer droplet and polymer particles. The variation of the volume fraction of interfacial layer was varied by the level of monomer concentration in the reaction system. At the very low monomer concentration the polymerization is supposed to proceed in the thick emulsifier palisade layer (mixed micelles). The in- 
crease in the concentration of monomer decreases the volume fraction of thick layer and on the contrary increases the volume fraction of monomer and the polymerisation within the monomer or polymer phase. The high oil-solubility of non-ionic emulsifier is expected to influence the polymerisation process via the chain transfer and exit events of transferred radicals. The polymerization was initiated by the watersoluble initiator ammonium peroxodisulfate (APS) and oil-soluble initiator 2,2'-azobisizobutyronitrile $($ AIBN). The water-phase APS-initiated polymerization initiates the formation of surface-active oligomers which accumulate around the particles in the form the electrical double layer. The variation in properties of surface active oligomers th the experimental conditions is in the close contact with the polymerisation process. This is not the case with AIBN which initiate the polymerisation in the monomer phase, does not form surface active oligomers and does not initiate any defects in the thick interfacial layer.

\section{EXPERIMENTAL}

\section{Materials}

Commercially available styrene (St) (Fluka) was purified by distillation under reduced pressure. Extra pure ammonium peroxodisulfate (APS, Fluka) and 2,2'azobisizobutyronitrile (AIBN, Fluka) and $\mathrm{NaHCO}_{3}$ were used as supplied. The nonionic emulsifier used was the reagent-grade Tween 20 ( $\mathrm{Tw} 20$, polyoxy ethylene sorbitan monolaurate, provided by Serva in the form of a $97 \%$ aqueous solution). Doubly distilled water was used as a polymerization medium.

\section{Recipe and Procedures}

Batch emulsion polymerizations of styrene were carried out at $60^{\circ} \mathrm{C}$ with the recipe comprising $100 \mathrm{~g}$ water, $5 \mathrm{~g}$ Tw 20 and $0.016 \mathrm{~g} \mathrm{NaHCO}_{3}$. The monomer dispersions were prepared by dissolving the mixture of emulsifier (Tw 20) and styrene in water $(100 \mathrm{~g})$ and mixed with a mechanical agitator at $400 \mathrm{rpm}$ for $10 \mathrm{~min}$. The amounts of styrene and initiator (APS,
AIBN) varied as shown later. The monomer conversion was determined by the dilatometric method and the final conversion was checked by gravimetry. The isolation of polymer product from the systems containing a low level of monomer was not quantitative because the precipitation/dissolution cycle was accompanied by the formation of fine dispersion. This procedure was improved by dialysis of polymer latexes. The polymerization technique, the preparation of polymer latex for particle size measurements and the particle number estimation were the same as described earlier. ${ }^{13-16}$ The measurements of average size of polymer particles were performed by a static and dynamic light scattering method and SEM measurements as described earlier. ${ }^{17,18}$ Limiting viscosity numbers were determined with Ubbelohde viscometer in toluene at $25^{\circ} \mathrm{C}$ and used to estimate the viscosityaverage molecular weights. ${ }^{19,20}{ }^{13} \mathrm{C}$ NMR spectra obtained on deuterated chloroform solutions were recorded on a Brucker spectrometer at $20^{\circ} \mathrm{C}$.

\section{Ostwald Ripening Measurements}

The emulsion was prepared by dissolving the mixture of emulsifier ( $\mathrm{Tw} 20$ ) and styrene in water and mixed with a mechanical agitator at $400 \mathrm{rpm}$ for $10 \mathrm{~min}$. The average monomer droplet size of diluted emulsion as a function of aging time was determined by the dynamic light scattering method. The colloidal stability of the (non-diluted) emulsion product was monitored by placing about $100 \mathrm{~mL}$ sample in a glass vial at $25^{\circ} \mathrm{C}$. The position of the creaming line from the bottom of the sample and the time necessary for a visible monomer phase on the top of sample to appear were then recorded.

\section{RESULTS AND DISCUSSION}

\section{The Monomer Droplet Degradation}

The original monomer emulsion containing up to ca. $4 \mathrm{~g}$ styrene $/ 100 \mathrm{~mL}$ water did not show any phase separation after 5 days aging at a room temperature (Table I). Furthermore, the size of diluted miniemul-

Table I. Variation of kinetic, colloidal and molecular weight parameters in the sterically stabilized emulsion polymerization with styrene $_{\text {low }}$ concentration. $^{\text {a }}$

\begin{tabular}{|c|c|c|c|c|c|c|c|c|c|c|c|c|}
\hline \multirow{2}{*}{\multicolumn{2}{|c|}{$\begin{array}{c}\text { [Styrene] } \\
(\mathrm{g} / 100 \mathrm{~g} \text { water }) \\
\left(\mathrm{mol} \mathrm{dm}^{-3}\right)\end{array}$}} & \multicolumn{2}{|c|}{$\begin{array}{c}R_{\mathrm{p}, \max } \times 10^{4} \\
\left(\mathrm{~mol} \mathrm{dm}^{-3} \mathrm{~s}^{-1}\right)\end{array}$} & \multicolumn{2}{|c|}{$\begin{array}{l}\text { Conv.f } \\
(\%)\end{array}$} & \multicolumn{2}{|c|}{$\begin{array}{l}d_{\mathrm{p}, \mathrm{f}} \\
(\mathrm{nm})\end{array}$} & \multicolumn{2}{|c|}{$\begin{array}{c}N_{\mathrm{p}, \mathrm{f}} \\
\times 10^{16} / \mathrm{dm}^{3}\end{array}$} & \multirow{2}{*}{$\begin{array}{l}k_{\text {des }}^{\prime} \\
\times 10^{13}\end{array}$} & \multirow[t]{2}{*}{$k_{\text {des }}$} & \multirow{2}{*}{$\begin{array}{r}M_{\mathrm{V}} \\
\times 10^{6}\end{array}$} \\
\hline & & 1) & 2) & 1) & 2) & 3) & 4) & 3) & 4) & & & \\
\hline 0.834 & 1.43 & 1.94 & 1.4 & 130 & 93 & 28 & 36 & 13.8 & 40 & 7.36 & 0.14 & 1.2 \\
\hline 1.668 & 2.48 & 2.9 & 2.4 & 115 & 95 & 35 & 39 & 14.1 & 56 & 7.36 & 0.092 & 2.3 \\
\hline 3.0 & 3.6 & 4.6 & 4.6 & 91 & 90 & 43 & 42 & 13.7 & 64 & 7.36 & 0.061 & 3.2 \\
\hline 3.34 & 3.86 & 4.9 & 4.8 & 85 & 87 & 45 & 43 & 13.3 & 62 & 7.36 & 0.055 & 3.2 \\
\hline
\end{tabular}

${ }^{\mathrm{a}}$ Recipe: $100 \mathrm{~g}$ water, $5 \mathrm{~g}$ Tw $20,0.015 \mathrm{~g}$ APS, $0.016 \mathrm{~g} \mathrm{NaHCO}_{3}$, temp. $=60{ }^{\circ} \mathrm{C}$. Subscript $\mathrm{f}$ denotes the final value, 1) uncorrected values of $R_{\mathrm{p}}$ and conversion (determined by dilatometric method), 2) corrected values of $R_{\mathrm{p}}\left(R_{\mathrm{p}, \text { corr }}\right)$ and conversion (determined by gravimetric method), 3) at ca. $20 \%$ conversion, 4) at final conversion. 
sion (volume/volume, emulsion/water, 1/50) droplet did not change after $c a .2$ or $3 \mathrm{~h}$ aging. At a higher concentration of monomer $>4 \mathrm{~g}$ monomer $/ 100 \mathrm{~g}$ water the phase separation appears and the rate of monomer degradation is proportional to the monomer concentration. The monomer phase appears at the top of sample appears in the system containing $c a .6 \mathrm{~g}$ monomer/ $100 \mathrm{~g}$ water after 3 days aging and in the sample containing $c a .20 \mathrm{~g}$ monomer $/ 100 \mathrm{~g}$ water after $c a$. $3 \mathrm{~h}$. All the studied systems were enough stable to use dilatomery to follow the polymerization history. The transfer of styrene from the smaller droplets to larger ones initiates the increase of the average droplet size and the phase separation or the appearance of the monomer layer on the top of sample. The strong suppression of the Ostwald ripening ${ }^{21}$ in both the original (concentrated) and diluted sterically stabilized styrene emulsions suggests that some physical processes are occurring. There are a number of possible processes that could be operative. First, it is possible that association of Tw 20 forms colloids other than the spherical micelles at relatively high emulsifier concentration and these transport oil differently. ${ }^{22}$ Secondly, it is possible that the nonionic emulsifier forms multilayers around the monomer droplets, which retards the movement of oil molecules from the droplets to the surrounding aqueous phase. Third, the data obtained in the sterically stabilized emulsion systems ${ }^{23}$ indicate that nonionic emulsifier can act as hydrophobe especially at high temperature. Furthermore, the presence of inverse micelles in the o/w monomer emulsion stabilized by nonionic emulsifier can be somehow related to the increased stability of monomer droplets. ${ }^{24}$

\section{Polymerization Rate}

The conversion-time data for the sterically stabilized emulsion polymerization of styrene (St) initiated by a water-soluble initiator (APS) are shown in Figure 1 . The polymerizations were carried out at very low monomer concentrations. In these systems the final conversion estimated by dilatometry was much above $100 \%$ (Table I). The deviation was inversely proportional to the styrene concentration or the weight ratio St/Tw 20 (the concentration of Tw 20 was kept constant), that is, the smaller the monomer concentration the larger the final conversion $\left(\right.$ Conv. $\left._{.^{f}} / \%\right)$ :

$$
\begin{aligned}
& 130 /(0.17), 115 /(0.33), \\
& 91 /(0.6), 85 /(0.67)
\end{aligned}
$$$$
\left(\mathrm{Conv}_{. \mathrm{f}} / \%\right) /(\text { wt. ratio St/Tw 20) : }
$$

The overestimated conversion can be related to the solubilization of monomer within the emulsifier palisades. In the run with the weight ratio St/Tw $20=$

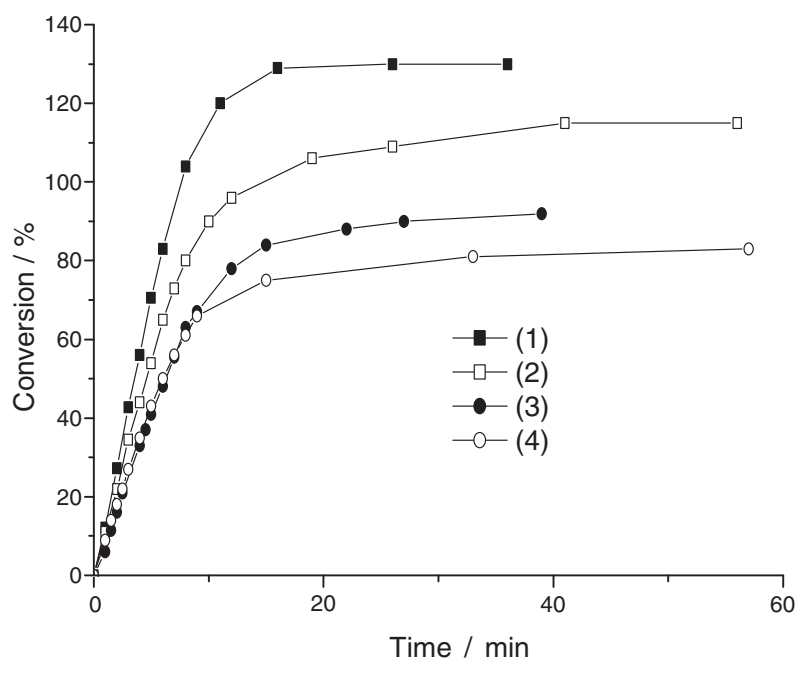

Figure 1. Variation of monomer conversion in the emulsion polymerization of styrene (St) with the reaction time and concentration of monomer. Recipe: $100 \mathrm{~g}$ water, $5 \mathrm{~g}$ Tw 20, $0.015 \mathrm{~g}$ APS, $0.016 \mathrm{~g} \mathrm{NaHCO}_{3}$, temp. $=60^{\circ} \mathrm{C}$.

0.17 the larger part of monomer is solubilized in the emulsifier palisades. The presence of a larger portion of styrene either in the aqueous phase ( $c a .5 \mathrm{wt} . \%$ of the total for the lowest concentration) or within "emulsifier palisades", with a greater molar volume than in the bulk, might be responsible for the overestimated conversion..$^{25}$ The variation in partial volume of solutes in the micellar phase is ascribed to the hydrophilic or hydrophobic interaction between some groups of solute and emulsifier. ${ }^{26}$ The reverse behavior (the appearance of the limiting conversion) was observed in the (micro)emulsion polymerization containing a very small amount of butyl acrylate where the limiting conversion results from the hydrophilic interaction between the polar groups of emulsifier (sodium dodecyl sulfate, SDS) and butyl acrylate. ${ }^{27}$

At a very low monomer concentration, the monomer can be consumed by both the solute and propagating radicals. ${ }^{28}$ The nonionic emulsifier was reported to accelerate the decomposition of peroxodisulfate accompanied by the formation of transferred emulsifier radicals. ${ }^{29}$ The participation of transferred radicals in the propagation can lead to the incorporation of emulsifier units to the final polymer product. The ${ }^{13} \mathrm{C}$ NMR analysis of polymer product formed for the lowest monomer concentration confirms the presence of polyoxyethylene chains (at $70.2 \mathrm{ppm}$ ) in the polymer product. The polymer contains emulsifier PEO units even after the dialysis and the precipitation procedure. Scheme 1 indicates that the growing radicals $\left(\mathrm{P}^{\bullet}\right)$ within emulsifier palisades induces the chain transfer to emulsifier (E) molecules and the incorporation of emulsifier moieties into the polymer product:

The conversion determined by gravimetric method 


$$
\begin{aligned}
\mathrm{P}^{\bullet}+\mathrm{E} & \rightarrow \mathrm{P}+\mathrm{E}^{\bullet} \\
\mathrm{P}^{\bullet}+\mathrm{E}^{\bullet} & \rightarrow \mathrm{P}-\mathrm{E} \\
\mathrm{E}^{\bullet}+\mathrm{nM} & \rightarrow \mathrm{E}-\mathrm{P}^{\bullet}
\end{aligned}
$$

\section{Scheme 1.}

was much below $100 \%$ (Table I). The final conversion below $100 \%$ can be attributed to the loss of low-molecular weight products caused by both the dialysis of polymer latex and the precipitation procedure.

Variations of the polymerization rate with the styrene concentration are illustrated in Figure 2 and Table I. These data show that the polymerization consists of three rate intervals. First the rate of polymerization abruptly increases to the maximum reaching ca. 15-20\% conversion (Interval 1). The abrupt increase in the initial polymerization rate $\left(R_{\mathrm{p}, \text { init }}\right)$ can be attributed to the robust particle nucleation. The high concentration of Tw 20 and the large weight ratio Tw 20/styrene is connected with the large number of micelles and particles and the high degree of compartmentalization of reaction loci. The rate of polymerization in the second interval somewhat decreases with conversion and the decrease is proportional to the monomer concentration, that is, the slope of the $R_{\mathrm{p}}$ $v s$. conversion line becomes more negative with increasing the monomer concentration. The rate of polymerization in the third rate interval abruptly decreases with conversion. The onset of Interval 3 (Conv.onset) is shifted to the lower conversion with increasing the monomer concentration:

$$
\text { Conv.onset }(\%) / \text { the run number (Figure 2) : }
$$

$$
72 /(1), 67 /(2), 65 /(3), 50 /(4)
$$

The distinct two rate-intervals were observed in the microemulsion polymerization of styrene at the large weight ratio (emulsifier plus coemulsifier)/styrene stabilized by SDS and 1-pentanol. ${ }^{30}$ Under a low monomer concentration the oil cores in microdroplets disappear early in the microemulsion polymerization (4\% conversion). Above this critical conversion the monomer is located partly in the polymer particles and the aqueous phase and the rest in the micelles (mixed micelles, emulsifier palisades). The strong decrease in the polymerization rate at higher conversions was attributed to the depressed entry efficiency of radicals into the "mixed" emulsifier/monomer micelles (micelles without monomer core) and decreased monomer concentration.

At a higher monomer concentration the initial increase in $R_{\mathrm{p}}$ is more pronounced and therefore the decrease in $R_{\mathrm{p}}$ with conversion (in the second interval)

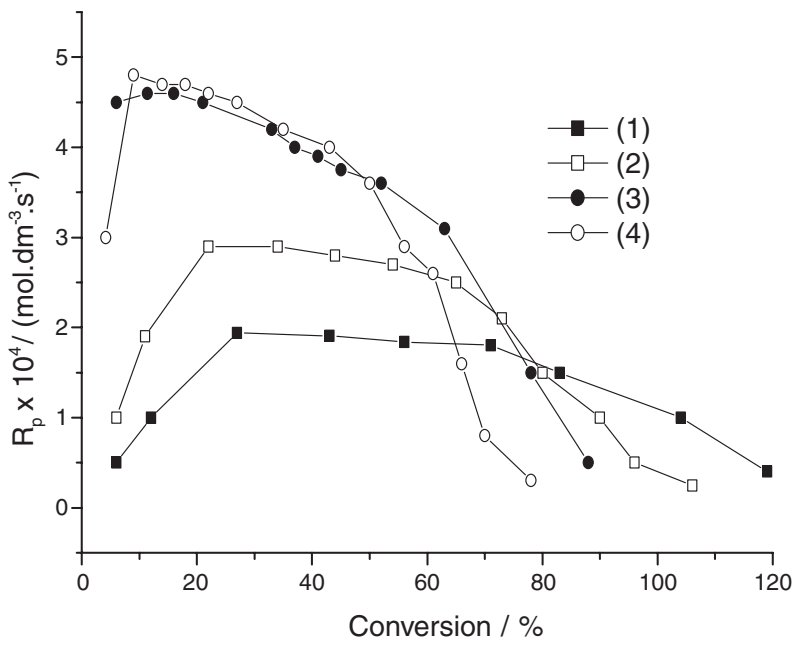

Figure 2. Variation of the rate of emulsion polymerization of styrene with monomer concentration and conversion. Styrene (g)/ 100 g water: 0.834 (1), 1.668 (2), 3.0 (3), 3.34 (4) For other conditions see Fig. 1.

should be more pronounced (Figure 2). Indeed, the results show that the slope of the $R_{\mathrm{p}} v s$. conversion line becomes more negative with increasing the monomer concentration. The two-rate intervals (in the microemulsion polymerization) are connected with the predominant adsorption of initiating radicals by the monomer-swollen micelles or microdroplets. The consumption of monomer in Interval 3 (reaching the glassy state) decreases the polymerization rate.

Figure 2 and Table I show that $R_{\mathrm{p} \text {,max }}$ strongly rises with the monomer concentration as follows:

$$
\begin{aligned}
& R_{\mathrm{p}, \max } \propto[\text { Styrene] }]^{0.67} \\
& \text { and } R_{\mathrm{p}, \text { max }, \text { corr }} \propto[\text { Styrene] }]^{0.91}
\end{aligned}
$$

This behavior deviates from both the micellar model ${ }^{31}$ and homogeneous nucleation ${ }^{32}$ where the maximal rate of polymerization $\left(R_{\mathrm{p}, \max }\right.$, Interval 2$)$ slightly increases or is independent of monomer concentration. The chain transfer (agents) events should not influence the kinetics of free radical polymerization of monomers in homogeneous bulk or solutions systems, although they do reduce the molecular weight of the polymer formed. This is not true for the emulsion polymerization where a chain-transfer agent significantly reduces not only the molecular weight of the polymer formed but also the rate of polymerization. This reduction in rate arises from the breakdown in the extent of compartmentalization of the free radicals in the latex particles. ${ }^{33}$ The PEO-type emulsifier is supposed to act as a chain transfer agent promoting the exit of radicals. ${ }^{29}$

The specific desorption rate constant $k_{\mathrm{des}}\left(\mathrm{cm} \mathrm{s}^{-1}\right)$ is related to $k_{\text {des }}^{\prime}\left(\mathrm{cm}^{2} \mathrm{~s}^{-1}\right)$ by the following equations: ${ }^{34-37}$ 
Table II. Kinetic parameters for emulsion polymerization of styrene.

\begin{tabular}{lll}
\hline Parameter & Numerical Value & Ref. \\
\hline$[M]_{\mathrm{p}}$ & $5.2 \mathrm{M}$ & 38 \\
\hline$k_{\mathrm{p}}$ & $\begin{array}{l}4.7 \times 10^{11} \exp (-9805 / R T) \mathrm{dm}^{3} \mathrm{~mol}^{-1} \\
\min ^{-1}\end{array}$ & 39 \\
\hline$k_{\mathrm{fm}}$ & $\begin{array}{l}1.486 \times 10^{12} \exp (-17543 / R T) \mathrm{dm}^{3} \\
\mathrm{~mol}^{-1} \mathrm{~min}^{-1}\end{array}$ & 36,37 \\
\hline$a^{\prime}$ & 1400 & 40 \\
\hline$D_{\mathrm{w}}$ & $1.76 \times 10^{-9} \mathrm{dm}^{2} \mathrm{~min}^{-1}$ & 36 \\
\hline$D_{\mathrm{p}}$ & $1.76 \times 10^{-12} \mathrm{dm}^{2} \mathrm{~min}^{-1}$ & 36 \\
\hline
\end{tabular}

$$
\begin{aligned}
& k_{\mathrm{des}} a_{\mathrm{p}} / v_{\mathrm{p}}=k_{\mathrm{des}}^{\prime} /\left[(\pi / 6)^{2 / 3} \mathrm{~d}_{\mathrm{p}}^{2}\right] \\
& k_{\mathrm{des}}^{\prime}=k_{\mathrm{fm}} / k_{\mathrm{p}}^{\bullet}\left[12\left[(\pi / 6)^{2 / 3} D_{\mathrm{w}} /\left(a^{\prime}+D_{\mathrm{w}} / D_{\mathrm{p}}\right)\right]\right.
\end{aligned}
$$

where $d_{\mathrm{p}}$ is the diameter of a monomer-swollen particle, $v_{\mathrm{p}}$ volume of monomer-swollen particles, $a_{\mathrm{p}}$ surface area of a monomer-swollen particle, $k_{\mathrm{fm}}$ monomer chain transfer constant, $k_{\mathrm{p}}^{\bullet}$ reinitiation rate constant for monomeric radicals, $D_{\mathrm{w}}$ and $D_{\mathrm{p}}$ diffusion rate coefficients of the monomeric radicals in the aqueous and particle phases, respectively, and $a^{\prime}$ the partition coefficient for monomeric radicals between the particle phase and the aqueous phase (see Table II). The values of $d_{\mathrm{w}}$ and $\rho_{\mathrm{m}}$ were used to calculate $v_{\mathrm{p}}$ and $a_{\mathrm{p}}$ by simple mass balance.

The parameter $k_{\text {des }}^{\prime}$ is independent of particle size and, therefore, it is reasonable to compare $k_{\text {des }}^{\prime}$ with the literature. The literature values of $k_{\text {des }}^{\prime}$ are in the range of $3.9 \times 10^{-14}-4.8 \times 10^{-13} \mathrm{~cm}^{2} \mathrm{~s}^{-1}$ for the electrostatically stabilized polymerization of styrene at $60{ }^{\circ} \mathrm{C} .{ }^{36,37}$

The values of $k_{\text {des }}^{\prime}$ for the sterically stabilized emulsion polymerization of styrene are slightly larger (Table I) than those for the electrostatically stabilized emulsion polymerization of styrene. ${ }^{36}$ The data in Table I, however, differ from those reported for the electrosterically stabilized emulsion polymerization of styrene where the desorption of radicals was de- pressed. ${ }^{8-10}$ The decreased desorption of radicals was attributed to the thick emulsifier layer formed by the graft copolymer at the polymer particle surface. This difference between the present data and the literature ones might result from the difference in the solubility, the molecular weight and mobility of the stabilizers used. The partitioning of Tween 20 between the monomer and water phases, its high mobility and the chain transfer activity favour both the chain transfer and desorption of radicals. This may not be a case for the high molecular weight copolymer. ${ }^{8-10}$ The reduction in the polymerization rate with increasing the weight ratio of emulsifier and monomer can arise from the breakdown in the extent of compartmentalization of the free radicals in the latex particles and the increased exit of radicals. The decreased extent of compartmentalization of radicals is accompanied with the shapes of the conversion and polymerization rate curves (Figures 1 and 2) typical for the microemulsion polymerization characterized by the strong radical desorption.

The sterically stabilized emulsion polymerization was also studied at the higher monomer concentration in which the particles consist of the comparable volume fractions of emulsifier layer and monomer (polymer) core (Table III). Figure 3 shows that the shape of conversion curves is similar to those in Figure 1, that is, the conversion time curves are concave downward which deviates from the classical emulsion polymerization. The final conversion is nearly inversely proportional to the monomer concentration. The depressed rate of polymerization at higher conversion can be discussed in terms of the immobilization of monomer in the glassy polymer particle matrix, the depressed water-phase polymerization and the depressed entry rate efficiency of more hydrophilic radicals formed at higher conversions.

The rates of emulsion polymerization of styrene at different monomer concentrations are illustrated in Figure 4 and Table III. The shape of the rate $v s$. con-

Table III. Variation of kinetic, colloidal and molecular weight parameters in the sterically stabilized emulsion

\begin{tabular}{|c|c|c|c|c|c|c|c|c|c|c|}
\hline \multirow{2}{*}{\multicolumn{2}{|c|}{$\begin{array}{c}\text { [Styrene] } \\
(\mathrm{g} / 100 \mathrm{~g} \text { water }) \\
\left(\mathrm{mol} \mathrm{dm}^{-3}\right)\end{array}$}} & \multirow{3}{*}{$\begin{array}{c}\begin{array}{c}R_{\mathrm{p}, \max } \\
\times 10^{4} \\
\left(\mathrm{~mol} \mathrm{dm}^{-3} \mathrm{~s}^{-1}\right)\end{array} \\
7.7\end{array}$} & \multirow{3}{*}{$\begin{array}{l}\text { Conv.f } \\
(\%) \\
85\end{array}$} & \multicolumn{2}{|c|}{$\begin{array}{l}d_{\mathrm{p}, \mathrm{f}} \\
(\mathrm{nm})\end{array}$} & \multicolumn{2}{|c|}{$\begin{array}{c}N_{\mathrm{p}, \mathrm{f}} \\
\times 10^{16} / \mathrm{dm}^{3}\end{array}$} & \multirow{3}{*}{$\begin{array}{c}k_{\text {des }}^{\prime} \\
\times 10^{13} \\
7.36\end{array}$} & \multirow{3}{*}{$\begin{array}{c}k_{\mathrm{des}} \\
0.037\end{array}$} & \multirow{3}{*}{$\begin{array}{r}M_{\mathrm{v}} \\
\times 10^{6} \\
3.6\end{array}$} \\
\hline & & & & \multirow{2}{*}{$\frac{1)}{55}$} & \multirow{2}{*}{$\begin{array}{l}\text { 2) } \\
52\end{array}$} & \multirow{2}{*}{$\begin{array}{c}\text { 1) } \\
13.1\end{array}$} & \multirow{2}{*}{ 2) } & & & \\
\hline 6 & 5.11 & & & & & & & & & \\
\hline 8.3 & 5.77 & 11.1 & 98 & 65 & 64 & 11.0 & 54 & 7.36 & 0.027 & 4.2 \\
\hline 10.0 & 6.11 & 10.7 & 92 & 70 & 68 & 10.6 & 50 & 7.36 & 0.023 & 4.6 \\
\hline 13.3 & 6.59 & 9.2 & 81 & 80 & 79 & 10.2 & 38 & 7.36 & 0.018 & 4.9 \\
\hline 16.7 & 6.93 & 10.7 & 91 & 85 & 85 & 9.9 & 43 & 7.36 & 0.015 & 5.1 \\
\hline 20.0 & 7.16 & 10.2 & 80 & - & 115 & - & 18 & & & 5.2 \\
\hline
\end{tabular}
polymerization with styrene concentration. ${ }^{\mathrm{a}}$

${ }^{\mathrm{a}}$ Recipe: $100 \mathrm{~g}$ water, $5 \mathrm{~g}$ Tw 20, $0.015 \mathrm{~g}$ APS, $\left.0.016 \mathrm{~g} \mathrm{NaHCO}_{3}, 1\right)$ at $c a .20 \%$ conversion, 2) at final conversion, temp. $=60^{\circ} \mathrm{C}$. 


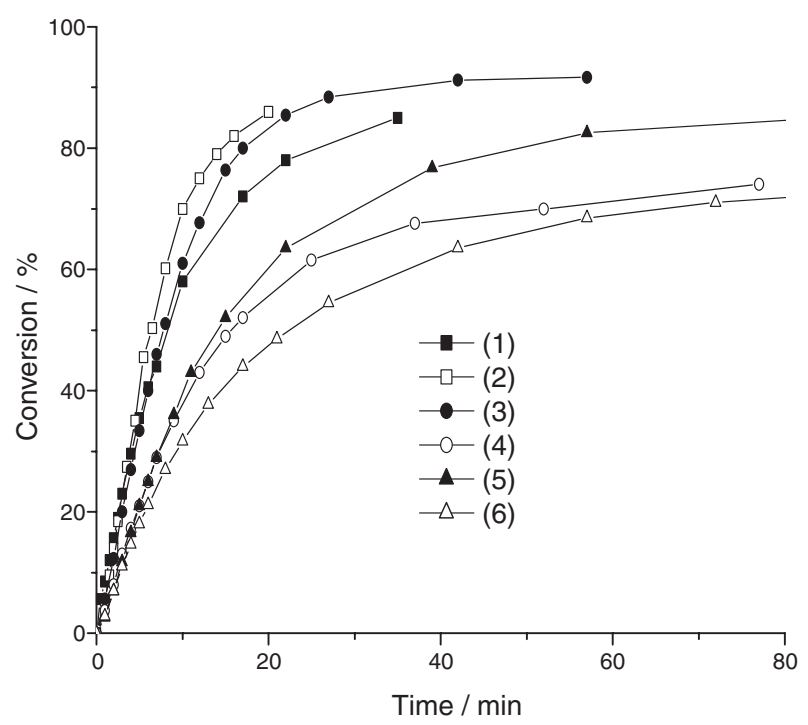

Figure 3. Variation of monomer conversion in the emulsion polymerization of St with the reaction time and concentration of monomer. Recipe: $100 \mathrm{~g}$ water, $5 \mathrm{~g}$ Tw 20, $0.015 \mathrm{~g}$ APS, $0.016 \mathrm{~g}$ $\mathrm{NaHCO}_{3}$. temp. $=60{ }^{\circ} \mathrm{C}$. Styrene $(\mathrm{g}) / 100 \mathrm{~g}$ water: $6.67(1), 8.3$ (2), 10.0 (3), 13.3 (4), 16.67 (5), 20.0 (6).

version curves varies with the monomer concentration. The first interval is very short and mostly ends at ca. $10 \%$ conversion. The second interval becomes less pronounced at higher monomer concentration. The onset of third rate interval varies as follows:

Conv.on $(\%) /$ the run number (Figure 4$)$ :

$$
50 /(1), 40 /(2), 45 /(3), 25 /(4), 35 /(5), 25 /(6)
$$

These data indicate that the second interval becomes less pronounced while the third interval becomes more pronounced at a higher monomer concentration. Figure 4 and Table III show that the maximal rate of polymerization $\left(R_{\mathrm{p}, \max }\right.$, the second rate interval) slightly increases with increasing the monomer con-

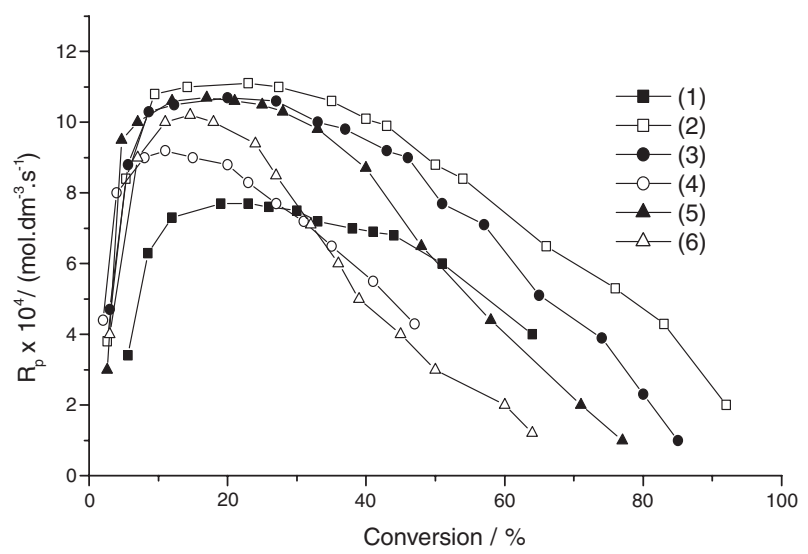

Figure 4. Variation of the rate of emulsion polymerization of styrene with monomer concentration and conversion. Styrene (g)/100 g water: 6.67 (1), 8.3 (2), 10.0 (3), 13.3 (4), 16.67 (5), 20.0 (6). For other conditions see Fig. 3. centration while the polymerization rate at higher conversion (at $c a$. 50-60\% conversion) decreases with increasing the monomer concentration:

$$
\begin{aligned}
& R_{\mathrm{p}, \max } \propto\left[{ }_{\text {Styrene }}\right]^{0.15} \\
& \quad \text { and } R_{\mathrm{p}, 50-60 \%} \propto[\text { Styrene }]^{-0.7}
\end{aligned}
$$

The slight increase in the rate can be attributed to the decrease in the $k_{\text {des }}$ values (Table III). When the gel effect becomes operative then the rate of polymerization does not vary with the initiator or monomer concentration. The absence of gel effect can be attributed to the decrease in the molecular weigh caused by the chain transfer events and the decreased extent of the compartmentalization of growing radicals. The increased accumulation of emulsifier in the monomer/ polymer particles with increasing the monomer concentration rises the desorption of radicals due to which decreases the rate of polymerization at $c a$. 50-60\% conversion.

The final conversions close to $100 \%$ were obtained in the runs with the lower APS concentrations $1 \times 10^{-4}$ and $5 \times 10^{-4}$ mol.dm ${ }^{-3}$ (Figures 5-7 and Table IV). Under such conditions the water-phase polymerization with a limited termination generates the hydrophobic oligomeric radicals which are effectively adsorbed by the hydrophobic particles. The limiting conversion was reached with higher APS concentrations $1 \times 10^{-3}$ and $1 \times 10^{-2}$ mol.dm ${ }^{-3}$, respectively. This is attributed to the increased water-phase termination due to which decreases the average chain length and hydrophobicity of oligomeric radicals. The decrease in the chain length of oligomeric radicals is much more pronounced at high conversion due to

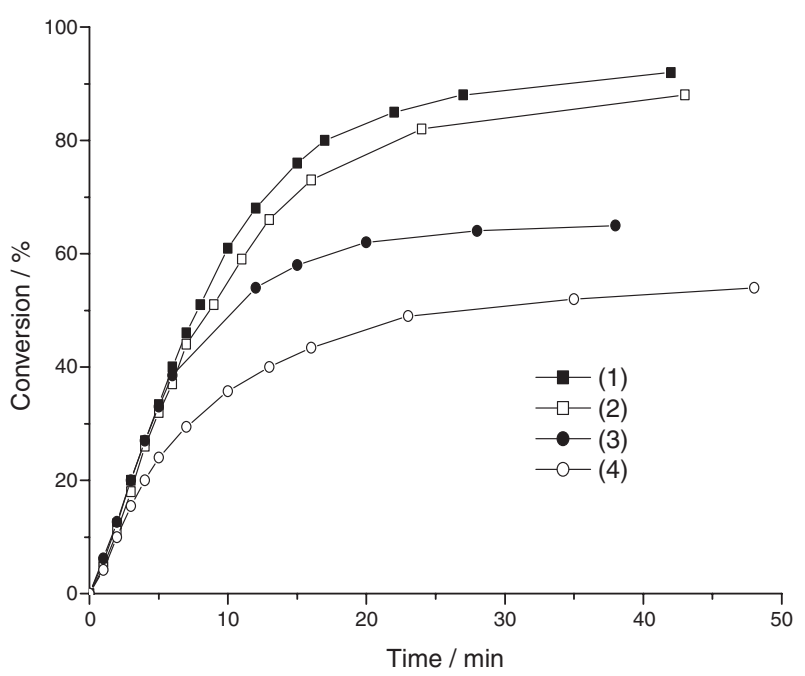

Figure 5. Variation of monomer conversion in the emulsion polymerization of St with the reaction time and APS concentration. Recipe: $100 \mathrm{~g}$ water, $10 \mathrm{~g}$ styrene, $5 \mathrm{~g}$ Tw 20 , temp. $=$ $60^{\circ} \mathrm{C}$. APS (g)/100 g water: 0.0023 (1), 0.012 (2), 0.028 (3), 0.228 (4). 


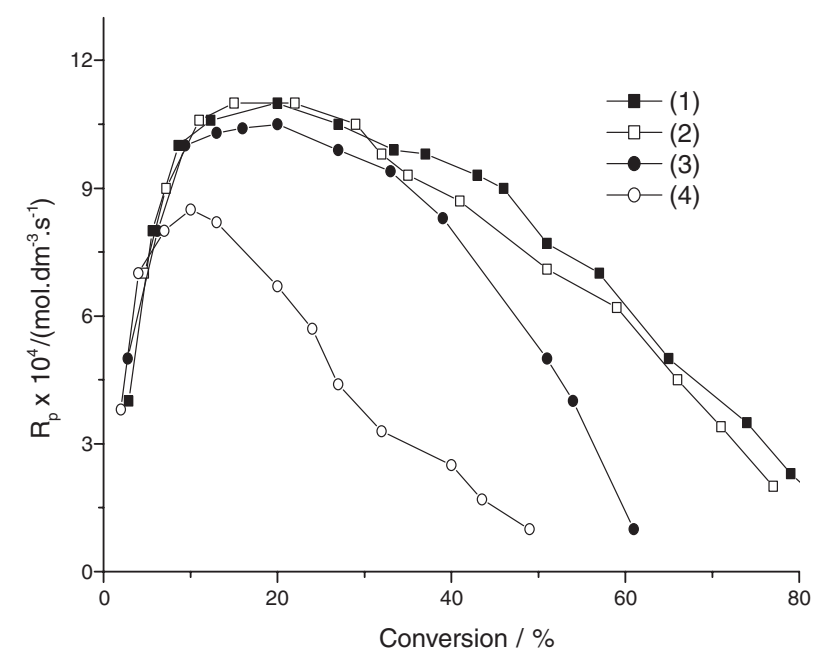

Figure 6. Variation of the rate of emulsion polymerization of styrene with conversion and APS concentration. APS $(\mathrm{g}) / 100 \mathrm{~g}$ water: 0.0023 (1), 0.012 (2), 0.028 (3), 0.228 (4).

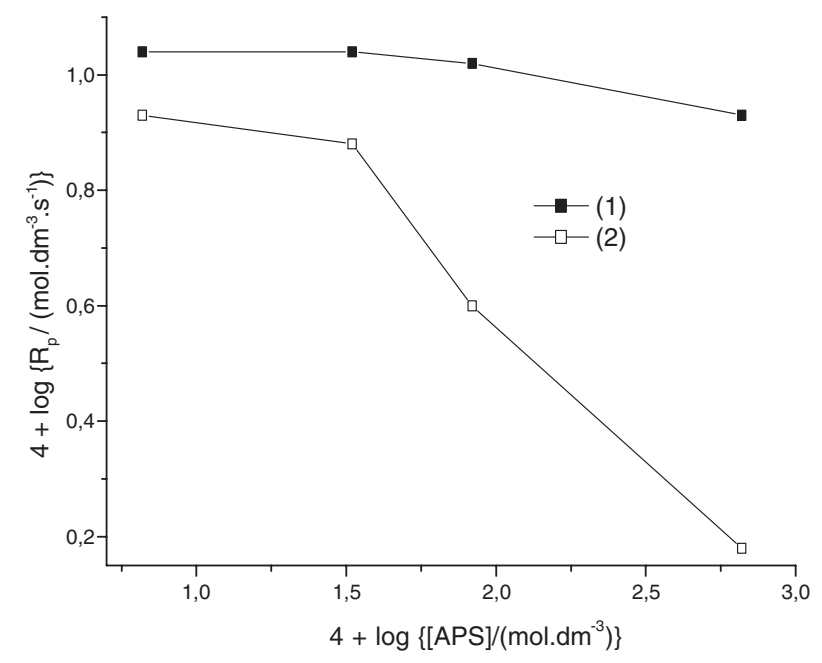

Figure 7. Variation of the rate of emulsion polymerization of styrene with APS concentration and conversion (the log-log plot). (1): at $c a$. 10-20\% conversion (Fig. 6), (2): at ca. 50-60\% conversion (Fig. 6).

Table IV. Variation of kinetic, colloidal and molecular weight parameters in the sterically stabilized emulsion polymerization of styrene (St) with APS concentration. ${ }^{\text {a }}$

\begin{tabular}{|c|c|c|c|c|c|c|c|c|c|}
\hline \multirow{2}{*}{$\begin{array}{c}{[\text { APS }]} \\
\times 10^{3} \\
\left(\mathrm{~mol} \mathrm{dm}^{-3}\right. \\
\text { water })\end{array}$} & \multirow{2}{*}{ 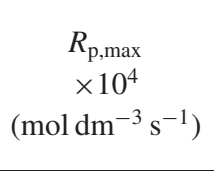 } & \multirow{2}{*}{$\begin{array}{c}\text { Conv.f }_{\text {f }} \\
(\%)\end{array}$} & & & \multicolumn{2}{|c|}{$\begin{array}{l}N_{\mathrm{p}, \mathrm{f}} \\
\times 10^{16} \\
/ \mathrm{dm}^{3}\end{array}$} & \multirow{2}{*}{$\begin{array}{l}k^{\prime}{ }_{\text {des }} \\
\times 10^{13}\end{array}$} & \multirow{2}{*}{$k_{\mathrm{des}}$} & \multirow{2}{*}{$\begin{array}{c}M_{\mathrm{V}} \\
\times 10^{6}\end{array}$} \\
\hline & & & 1) & 2) & 1) & 2) & & & \\
\hline 0.67 & 10.7 & 92 & 70 & 68 & 10.6 & 57 & 7.36 & 0.017 & 4.6 \\
\hline 3.33 & 11.0 & 93 & 65 & 55 & 13.2 & 97 & 7.36 & 0.016 & 3.9 \\
\hline 8.2 & 10.5 & 66 & 48 & 49 & 32.8 & 97 & 7.36 & 0.014 & 2.53 \\
\hline 66.6 & 8.5 & 56 & 70 & 75 & 10.6 & 23 & 7.36 & 0.017 & 0.9 \\
\hline
\end{tabular}

${ }^{\mathrm{a}}$ Recipe: $100 \mathrm{~g}$ water, $10 \mathrm{~g}$ styrene, $5 \mathrm{~g}$ Tw 20 , temp. $=60^{\circ} \mathrm{C}$.

the decreased monomer level as well propagation in the continuous phase. Furthermore, the PEO-type of nonionic emulsifier was reported to accelerate the decomposition of peroxodisulfate. ${ }^{29}$ The thick emulsifier layer, thus, can induce the formation of additional primary radicals (derived from peroxodisulfate initiator) which then take part in termination of radicals including the desorbed radicals. The ratio of rates of waterphase propagation and termination $\left(k_{\mathrm{p}}[M]_{\mathrm{w}} / k_{\mathrm{t}}\left[R^{\bullet}\right]_{\mathrm{w}}{ }^{2}\right)$ decreases with increasing conversion (or decreasing the monomer concentration), where $k_{\mathrm{t}}$ is the termination rate constant, $R^{\bullet}$ is the water-soluble radical and $M_{\mathrm{w}}$ is the monomer concentration in the aqueous phase. The decrease in the monomer concentration is accompanied by the formation of more hydrophilic radicals with higher activity for termination with the water-soluble primary radicals.

Variations of the polymerization rate with conversion and APS concentration are illustrated in Figures 6 and 7 and Table IV. The shape of the rate $v s$. conversion curve strongly varies with the initiator concentration. The stationary-state interval is more pronounced in the systems with the lower initiator concentrations. The high radical entry efficiency is reported for the electrostatically stabilized emulsion polymerization initiated by the low APS concentration. ${ }^{41}$ The formation of hydrophobic radicals throughout the polymerization and the efficient entry of radicals into particles keep the stationary state condition (the three rate intervals). On the contrary, the low radical entry efficiency is reported for the high APS concentration. ${ }^{41}$ The strong decrease in the polymerization rate beyond $c a$. 15-20\% conversion (the run 4 in Figure 6) can be attributed to the depressed radical entry efficiency caused by the hydrophilic nature of entered radicals and the thick emulsifier layer. The robust radical termination within the aqueous phase (including the thick interfacial layer), thus, decreases the radical entry rate efficiency.

The depressed radical entry efficiency is well documented by the dependences of the polymerization rate $v s$. the APS concentration and conversion (Figures 6 and 7, Table IV): 


$$
R_{\mathrm{p}, \max } \propto[\mathrm{APS}]^{\mathrm{x}=-0.06} \text { at } c a .20 \% \text { conversion (8) }
$$

and

$$
R_{\mathrm{p}} \propto[\mathrm{APS}]^{\mathrm{x}=-0.4} \quad \text { at } c a .50-60 \%
$$

The competition between the monomer and solute (emulsifier) for radicals varies with increasing conversion. At low conversion growing radicals add predominantly monomer while at high conversion growing radicals can interact also with emulsifier molecules and primary radicals. The slight decrease in the water-phase monomer concentration with increasing conversion from $20 \%$ to 50 or $60 \%$ can somewhat decrease both the water-phase polymerization and the chain length and hydrophobicity of oligomeric radicals but the decrease is not enough large to explain the observed behavior. ${ }^{42}$ The chain length and hydrophobicity of oligomeric radicals can be much more reduced by the primary radical termination. This is then responsible for the low radical entry rate efficiency. The lower the initiator concentration the larger the hydrophobicity of entering radicals. On the contrary, the higher the initiator concentration the larger the hydrophilicity of entering radicals. In the electrostatically stabilized emulsion polymerization the maximal rate of polymerization and the rate of polymerization at ca. 50-60\% conversion increase with increasing the APS concentration $(x=0.46){ }^{43}$ The data in Figure 6 and equations 8 and 9 strongly deviate from the electrostatically stabilized emulsion ${ }^{31}$ in which the $x$ values are positive in the range 0.2-0.5. The emulsifier palisade layer promotes the deactivation of radicals within the thick interface. The induced decomposition of APS by the interaction with the PEO chains can in-

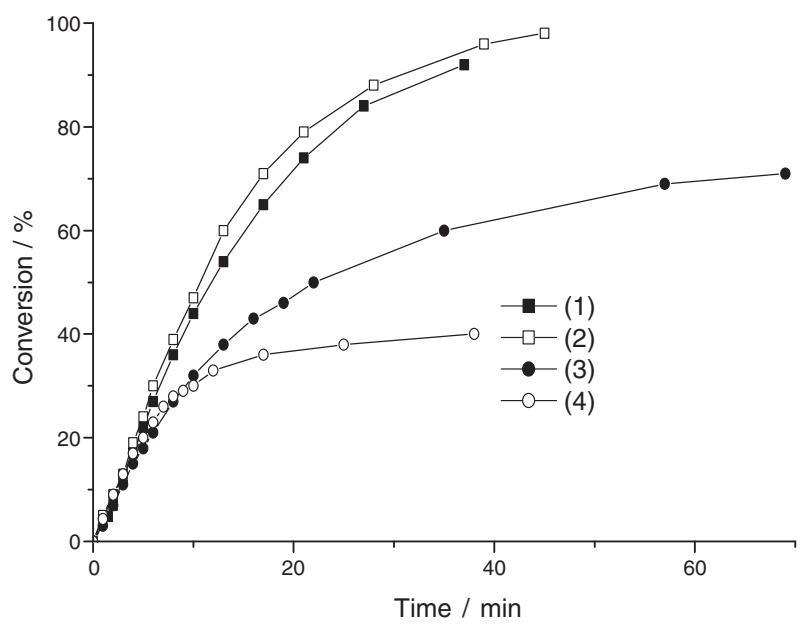

Figure 8. Variation of monomer conversion in the emulsion polymerization of St with the reaction time and concentration of AIBN. Recipe: $100 \mathrm{~g}$ water, $10 \mathrm{~g}$ styrene, $5 \mathrm{~g}$ Tw 20, temp. $=$ $60{ }^{\circ} \mathrm{C}$. AIBN (g)/100 g water: 0.00246 (1), 0.025 (2), 0.15 (3), 0.2463 (4).

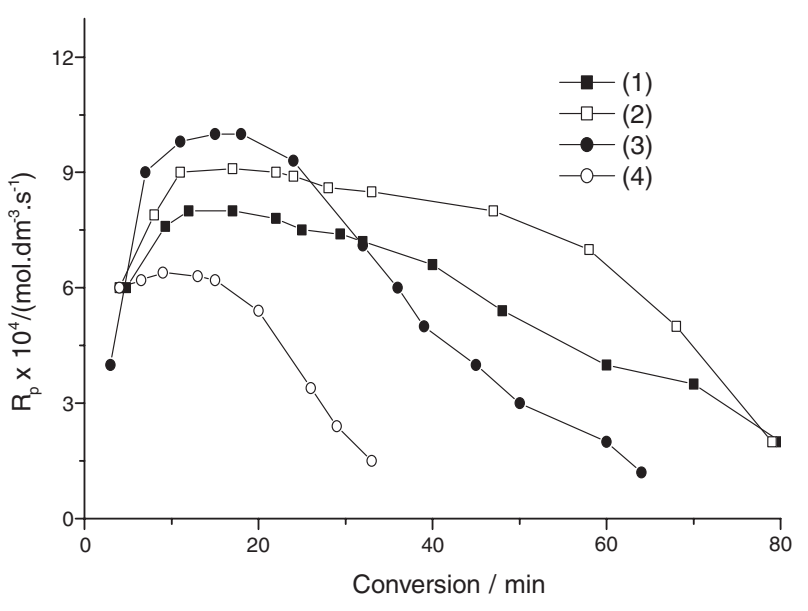

Figure 9. Variation of the rate of emulsion polymerization of styrene with AIBN concentration and conversion. AIBN (g)/100 g water: 0.00246 (1), 0.025 (2), 0.15 (3), 0.2463 (4). For other conditions see Fig. 8.

duce the primary radical termination in the thick interfacial layer. ${ }^{29}$ The values of $k_{\text {des }}^{\prime}$ are found to be nearly independent of APS concentration (Table IV). This can be attributed to the dominant role of emulsifier in the chain transfer and desorption mechanism.

The radical entry efficiency can be somewhat depressed by the repulsion between the negatively charged entering radicals and the electrical doublelayer around particles formed by charged oligomeric radicals (derived from APS). The radical entry events in the oil-soluble initiator-initiated emulsion polymerization are free of any by-side effects of charged moieties. The entry kinetics of non-charged radicals was studied on the scarcely-water soluble AIBN initiator whose radicals do not carry any charge. ${ }^{44}$ The final conversions close to $100 \%$ were obtained with the low AIBN concentrations $1.5 \times 10^{-4} \mathrm{~mol} \mathrm{dm}^{-3}$ and $1.5 \times 10^{-3} \mathrm{~mol} \mathrm{dm}^{-3}$, respectively (Figure 8). The slow polymerizations and limiting conversions were observed at higher AIBN concentrations $9 \times$ $10^{-3} \mathrm{~mol} \mathrm{dm}^{-3}$ and $1.5 \times 10^{-2} \mathrm{~mol} \mathrm{dm}^{-3}$, respectively. This can be attributed to the primary radical termination which decreases the polymerization rate at both low and high conversions. The polymerization rate is nearly independent of [AIBN] at low conversion ( $c a$. $20 \%$ ) (Figure 9, Table V)

$$
R_{\mathrm{p}, \max } \propto[\mathrm{AIBN}]^{-0.02}
$$

and decreases with increasing [AIBN] at $c a$. 50-60\% conversion

$$
R_{\mathrm{p}} \propto[\mathrm{AIBN}]^{-0.35}
$$

The reaction orders -0.02 and -0.35 for the AIBNinitiated polymerization (equations 10 and 11) are close to -0.06 and -0.4 obtained in the APS-initiated systems (equations 8 and 9). This behavior indicates 
Table V. Variation of kinetic, colloidal and molecular weight parameters in the sterically stabilized emulsion polymerization of styrene (St) with AIBN concentration. ${ }^{\mathrm{a}}$

\begin{tabular}{|c|c|c|c|c|c|}
\hline $\begin{array}{c}{[\mathrm{AIBN}]} \\
\times 10^{3} \\
\left(\mathrm{~mol} \mathrm{dm}{ }^{-3}\right. \\
\text { water })\end{array}$ & $\begin{array}{c}R_{\mathrm{p}, \max } \\
\times 10^{4} \\
\left(\mathrm{~mol} \mathrm{dm} \mathrm{dm}^{-3} \mathrm{~s}^{-1}\right)\end{array}$ & $\begin{array}{c}\text { Conv.f }_{\cdot f} \\
(\%)\end{array}$ & $\begin{array}{l}d_{\mathrm{p}, \mathrm{f}} \\
(\mathrm{nm}) \\
/ \mathrm{dm}^{3}\end{array}$ & $\begin{array}{l}N_{\mathrm{p}, \mathrm{f}} \\
\times 10^{16}\end{array}$ & $\begin{array}{l}M_{\mathrm{v}} \\
\times 10^{6}\end{array}$ \\
\hline 0.15 & 7.8 & 94 & 59 & 80 & 4.5 \\
\hline 0.6 & 9.1 & 97 & 51 & 127 & 2.7 \\
\hline 6.0 & 10.0 & 75 & 52 & 92 & 1.9 \\
\hline 15.0 & 6.4 & 40 & 54 & 44 & 1.5 \\
\hline
\end{tabular}

${ }^{\mathrm{a}}$ Recipe: $100 \mathrm{~g}$ water, $10 \mathrm{~g}$ styrene, $5 \mathrm{~g}$ Tw 20 , temp. $=60^{\circ} \mathrm{C}$.

that the primary-radical termination in both the water and oil phases influences the polymerization process in a similar way. The formation of surface active oligomeric radicals which are responsible for the particle nucleation is depressed at high APS concentration. The polymerization is also depressed at high AIBN concentration due to the primary radical termination (the entered radicals are deactivated by primary radicals derived from AIBN) and the cage effect. The similar behavior for both AIBN and APS can also result from the desorption of radicals. The formation of very fine polymer dispersions and the chain transfer to monomer and emulsifier favour the radical desorption. In both systems the concentration of monomer and emulsifier and the surface area of polymer particles is the same.

\section{Colloidal and Molecular Weight Parameters}

The particle size and the number of polymer particles vary with monomer and conversion as shown in Tables I and III and Figure 10. The particle size vs. conversion is found to be described by a curve with a minimum at $c a$. 30-50\% conversion (Table III, run with $10 \mathrm{~g}$ styrene $/ 100 \mathrm{~g}$ water):

$$
\begin{gathered}
\{\mathrm{D} / \mathrm{nm}\} /\{\text { Conversion }(\%)\}: \\
\text { 210/9,70/23, 65/30, } \\
64 / 52,67 / 75,68 / 92
\end{gathered}
$$

The particle size at $c a .20 \%$ conversion and at final conversion increases with increasing the monomer concentration. The number of polymer particles at ca. 20-30\% conversion is nearly independent of monomer concentration. The number of final polymer particles, however, increases with increasing the monomer concentration.

$$
N_{\mathrm{p}, \mathrm{f}} \propto\left[\text { Styrene }_{\text {low }}\right]^{\mathrm{x}=0.6}(\text { Table I) }
$$

and

$$
N_{\mathrm{p}, \mathrm{f}} \propto\left[\text { Styrene }_{\text {high }}\right]^{\mathrm{x}=-0.9} \quad(\text { Table III) }
$$

The micellar model proposes that the number of polymer particles is nearly independent of the monomer

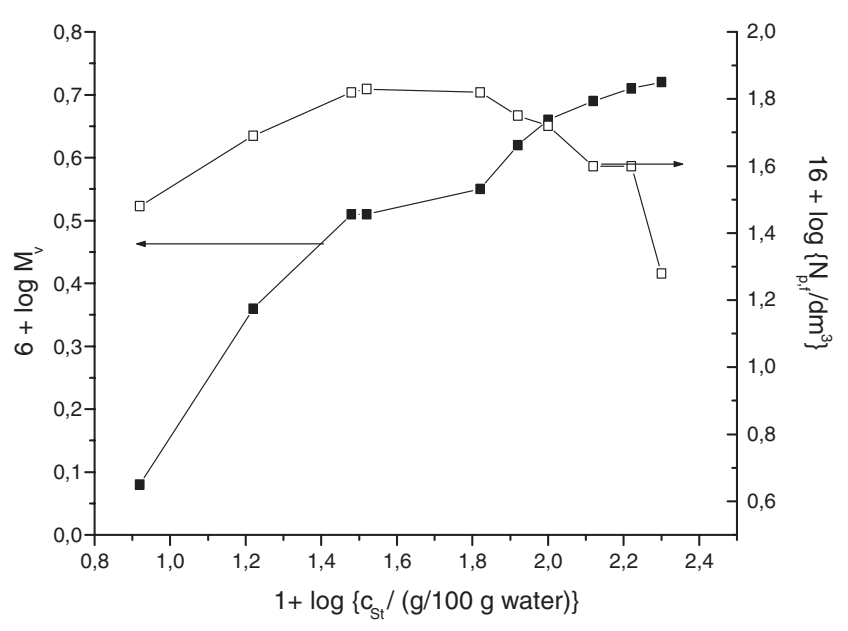

Figure 10. Variation of the viscosity-average molecular weight $\left(M_{\mathrm{v}}, \mathbf{\square}\right)$ and the number of polymer particles $\left(N_{\mathrm{p}, \mathrm{f}}, \square\right)$ with styrene concentration $\left(c_{\mathrm{St}}\right)$. a) Recipe: $100 \mathrm{~g}$ water, $5 \mathrm{~g} \mathrm{Tw} 20$, $0.015 \mathrm{~g}$ APS, $0.016 \mathrm{~g} \mathrm{NaHCO}_{3}$, temp. $=60^{\circ} \mathrm{C}$.

concentration. ${ }^{31,45}$ This is observed for the low conversion range where the reaction loci are saturated with the monomer. The polymerization in the emulsifier palisades zone is accompanied with the chain transfer and the accumulation of emulsifier moieties at the particle surface. This increases the colloidal stability and the number of polymer particles (Table I). At the higher monomer concentrations the increase in the particle size is more pronounced and the number of polymer particles strongly decreases with increasing the monomer concentration (Tables I and III, Figure 10).

Tables IV and V show that the dependence of the number of particles vs. initiator concentration is described by a curve with a maximum, that is, the number of particles first increases with increasing the initiator concentration and then after reaching the critical initiator concentration decreases. At the high APS concentration the depressed radical entry efficiency is accompanied with the low particle formation rate. In the AIBN-initiated polymerization the primary radical termination (the cage effect) is responsible for the low concentration of radicals and reaction loci or the 


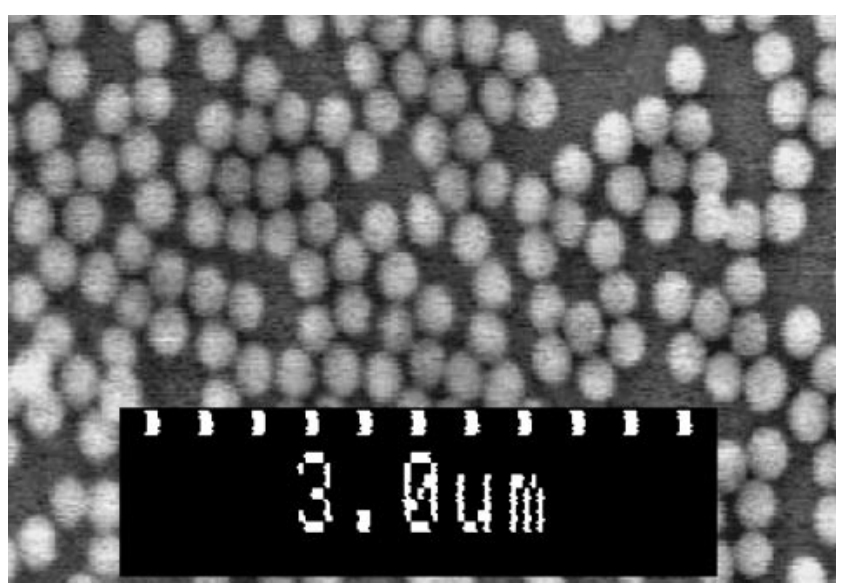

Figure 11. Scanning electron micrograph of polystyrene particles prepared by the emulsion polymerization of styrene initiated by AIBN. Recipe: $100 \mathrm{~g}$ water, $40 \mathrm{~g}$ styrene, $2 \mathrm{~g}$ Tw 20, $0.0164 \mathrm{~g}$ AIBN, $0.016 \mathrm{~g} \mathrm{NaHCO}_{3}$, temp. $=60^{\circ}$ C. $d_{\mathrm{n}}=219.8 \mathrm{~nm} ; d_{\mathrm{w}}=$ $224.0 \mathrm{~nm} ; d_{\mathrm{v}}=231.7 \mathrm{~nm}, \mathrm{IP}=d_{\mathrm{w}} / d_{\mathrm{n}}=1.019$.

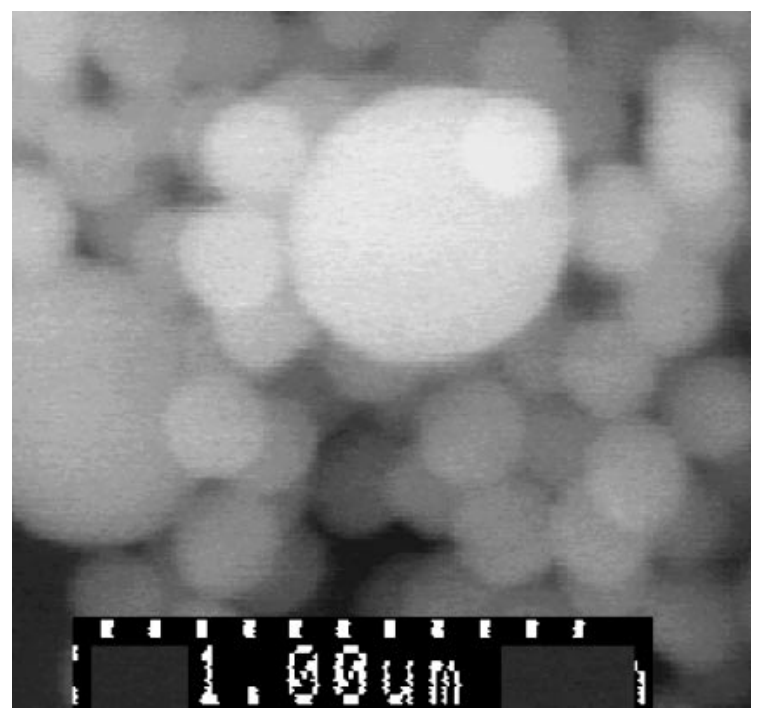

Figure 12. Scanning electron micrograph of polystyrene particles prepared by the emulsion polymerization of styrene initiated by APS. Recipe: $100 \mathrm{~g}$ water, $40 \mathrm{~g}$ styrene, $2 \mathrm{~g}$ Tw $20,0.023 \mathrm{~g}$ APS, $0.016 \mathrm{~g} \mathrm{NaHCO}_{3}$, temp. $=60^{\circ} \mathrm{C}$.

polymer particles. The larger number of polymer particles in the AIBN-initiated polymerization probably results from the homogeneous distribution of AIBN in the monomer swollen micells or emulsified droplets.

The hydrodynamic diameter $\left(d_{\mathrm{LS}}\right)$ of polystyrene particles was estimated to be $d=230 \mathrm{~nm}$ for the APS-initiated emulsion polymerization and $d=$ $225 \mathrm{~nm}$ for the AIBN-initiated emulsion polymerization. The SEM measurements (Figures 11 and 12) show that the relative monodisperse polymer particles are formed in the AIBN-initiated polymerization while in the APS-initiated polymerization two generations of small and large polymer particles appear (where $d_{\mathrm{n}}, d_{\mathrm{w}}$ and $d_{\mathrm{v}}$ denote number-, weight- and volume-average particle diameters and IP $\left(d_{\mathrm{w}} / d_{\mathrm{n}}\right)$ index polydispersity). The radicals derived from AIBN are supposed to start the polymerization in the monomer-swollen micelles or emulsified droplets (the initiator is homogeneously distributed in the monomerswollen micelles). The contribution of homogeneous nucleation initiated by the charged oligomeric radicals derived from APS is connected with the increased polydispersity. Furthermore, the accumulation of the surface-active oligomers at the particle surface in the form of the electrical double-layer around the particles can contribute to the larger polydispersity. The holes (ionic groups) at the particle surface disrupt the emulsifier palisade layer due to which increases the particle agglomeration.

The difference between the radius of bare particles $\left(d_{\mathrm{SEM}}\right)$ and that of emulsifier-coated particles (light scattering, LS, hydrodynamic size) is defined as the hydrodynamic layer thickness. The simple comparison of $d_{\mathrm{LS}}$ and $d_{\mathrm{SEM}}$ can be used to estimate the relative interfacial layer thickness $\left(\delta_{\text {intlayer }}\right)$ formed by Tw 20:

$$
\begin{aligned}
\delta_{\text {intlayer }} & =\left(d_{\mathrm{LS}}-d_{\mathrm{SEM}}\right) / 2 \\
& =(236 \mathrm{~nm}-231.7) / 2 \\
& =2.15 \mathrm{~nm} \quad(\text { for AIBN })
\end{aligned}
$$

The radius of gyration of PEO $\left(M_{\mathrm{w}}=1000 \mathrm{~g} \mathrm{~mol}^{-1}\right)$ was reported to be $c a .2 \mathrm{~nm}^{46}$ The hydrodynamic thickness of the PEO layer (Tw 20) estimated to be ca. $2.15 \mathrm{~nm}$ is in a good agreement with the theoretical value.

The viscosity-average molecular weights of polystyrene are found to increase with increasing the monomer concentration and the increase is much more pronounced at the lower monomer concentration range (Figure 10, Tables I and III):

$$
M_{\mathrm{v}} \propto\left[\text { Styrene }_{\text {low }}\right]^{0.8} \text { and } M_{\mathrm{v}} \propto\left[\text { Styrene }_{\text {high }}\right]^{0.3}
$$

In the solution polymerization the molecular weight of polymer is proportional to the first power of monomer concentration. ${ }^{47}$ The similar behavior seems to appear in the polymerization in which the solute (styrene) molecules are in the emulsifier palisades zone. Furthermore, the increase of the monomer concentration decreases the chain transfer events due to which the increase in the polymer molecular weight is more pronounced. The slight increase in the molecular weight at higher monomer concentrations remembers more the classical emulsion approach (the constant monomer concentration at the reaction locus).

The molecular weighs of polystyrene are smaller in the AIBN-initiated systems than in the APS-initiated ones which supports the presence of AIBN-derived 
radicals in the monomer phase and their participation in the bimolecular termination. Furthermore, $M_{\mathrm{v}}$ is inversely proportional to the initiator concentration.

$$
M_{\mathrm{v}} \propto[\mathrm{APS}]^{-0.37} \text { and } M_{\mathrm{v}} \propto[\mathrm{AIBN}]^{-0.22}
$$

\section{CONCLUSION}

From the foregoing discussion results that the rate of polymerization increases with the monomer concentration and the increase is much more pronounced at the lower monomer concentration, that is, when the polymerization proceeds in the emulsifier palisade layer. The dependence of the polymerization rate $v s$. conversion at high monomer and initiator concentrations is described by the two-rate intervals. At the high concentration of initiators (the water-soluble APS and the oil soluble AIBN) the limiting conversion, the slow polymerization and the smaller number of particles are found. This is discussed in terms of the formation of more hydrophilic radicals characterized by the low entry efficiency and the primary radical termination. The deviation from the micellar model was ascribed to the high oil-solubility of nonionic emulsifier and the chain transfer and desorption events. The values of desorption rate constant $k_{\text {des }}^{\prime}$ for the sterically stabilized emulsion polymerization of styrene are slightly larger than those for the electrostatically stabilized emulsion polymerization of styrene. The molecular weight of polystyrene is found to increase with increasing the monomer concentration and the increase is much more pronounced at the lower range of monomer concentration. The polymers are larger in the APS-initiated polymerization compared to that in the AIBN-initiated one. The increased radical termination within the monomer phase saturated with AIBN decreases the molecular weight. The molecular weight is inversely proportional to the initiator concentration which indicates the participation of radicals derived from both initiators in the termination mechanism.

Acknowledgment. This research is supported by Slovak Grand Agency (VEGA) through the grant number $2 / 1014 / 21$. The author wishes to thank Mrs. O. Juríková and K. Cínová for their assistance with the polymerization experiments, and Dr. I. Kostic (Institute of Informatics SAS) and Mrs. J. Capekova for SEM measurements.

\section{REFERENCES}

1. I. Piirma and M. Chang, J. Polym. Sci. Polym., Chem. Ed., 20, 489 (1982).

2. I. Capek, J. Barton, L. Q. Tuan, S. Svoboda, and V.
Novotny, Makromol. Chem., 188, 1723 (1987).

3. B. V. Deryagnin and L. D. Landau, Acta Physicochim. USSR, 14, 633 (1941).

4. E. J. W. Verwey and J. Th. G. Overbeek, "Theory of the Stability of Lyophobic Colloids," Elsevier, New York, N.Y., 1943 ,

5. D. H. Napper, "Polymeric Stabilization of Colloidal Dispersions," Academic Press, London, 1983.

6. R. H. Ottewill, J. Colloid Interface Sci., 58, 357 (1977).

7. J. M. Asua, Prog. Polym. Sci., 27, 1283 (2002).

8. E. Coen, R. A. Lyons, and R. G. Gilbert, Macromolecules, 29, 5128 (1996).

9. J. M. H. Kusters, D. H. Napper, G. G. Gilbert, and A. L. German, Macromolecules, 25, 7043 (1992).

10. C. M. Miller, E. D. Sudol, C. A. Silebi, and M. S. El-Aasser, J. Polym. Sci., Polym. Chem. Ed., 33, 1391 (1995).

11. J. Chudej and I. Capek, Polymer, 43, 1681 (2002).

12. I. Capek, J. Chudej, and S. Janíčková, J. Polym. Sci., 41, 804 (2003).

13. I. Capek, Makromol. Chem., 190, 789 (1989).

14. P. Potisk and I. Capek, Angew. Makromol. Chem., 222, 125 (1994).

15. I. Capek and J. Chudej, Polym. Bull., 43, 417 (1999).

16. I. Capek, Macromol. Symp., 179, 153 (2002).

17. I. Capek and W. Funke, Makromol. Chem., 191, 2549 (1990).

18. I. Capek, M. Riza, and M. Akashi, Makromol. Chem., 193, 2843 (1992).

19. C. E. H. Bawn, R. F. J. Freeman, and A. R. Kamaliddin, Trans. Faraday Soc., 46, 1107 (1950).

20. J. Brandrup and E. H. Immergut, "Polymer Handbook," 3rd ed., John Willey and Sons, Inc., New York, N.Y., 1989.

21. W. Ostwald, Phys. Chem., 37, 385 (1901).

22. G. T. Dimitrova, Th. F. Tadros, D. F. Luckham, and M. R. Kipps, Langmuir, 12, 315 (1996).

23. J. Weiss, Langmuir, 16, 6833 (2000).

24. F. K. Hansen and H. Fagerheim, Colloids Surf. A, 137, 217 (1998).

25. F. Franks, J. Chem. Soc., Faraday Trans. I, 73, 830 (1977).

26. R. Delisi, A. Lizzio, S. Milioto, and V. Turco Liveri, J. Solution Chem., 15, 623 (1986).

27. I. Capek, Adv. Colloid Interface Sci., 80, 85 (1999).

28. R. Asami, M. Takaki, K. Kyuda, and N. Sukenada, Polym. J., 13, 141 (1981).

29. M. Okubo and T. Mori, Makromol. Chem., Makromol. Symp., 31, 143 (1990).

30. J. S. Guo, E. D. Sudol, J. W. Vanderhoff, and M. S. El-Aasser, J. Polym. Sci., Polym. Chem. Ed., 30, 691 (1992).

31. W. V. Smith and R. H. Ewart, J. Am. Chem. Soc., 70, 3695 (1948).

32. R. M. Fitch and C. H. Tsai, J. Polym. Sci., Polym. Lett. Ed., 8, 703 (1970).

33. B. C. Y. Whang, G. Lichti, R. G. Gilbert, D. H. Napper, and D. F. Sangster, J. Polym. Sci., Polym. Lett. Ed., 18, 711 (1980).

34. J. Ugelstad, P. C. Mork, and J. O. Aassen, J. Polym. Sci., 5, 2281 (1967).

35. M. Nomura, H. Harada, K. Nakagawara, W. Eguchi, and S. Nagata, J. Chem. Eng. Jpn., 4, 160 (1971). 
36. H. C. Lee and G. W. Poehlein, Polym. Process. Eng., 5, 37 (1987).

37. C. S. Chern, S. Y. Lin, and T. J. Hsu, Polym. J., 31, 516 (1999).

38. E. Barthalome, H. Gerrens, R. Herbeck, and H. M. Weitz, Electrochemistry, 60, 334 (1956).

39. M. Buback, R. G. Gilbert, R. A. Hutchinson, B. Klumperman, F. D. Kuchta, B. G. Manders, K. F. O'Driscoll, G. T. Russell, and J. Schweer, J. Macromol. Chem. Phys., 196, 3267 (1995).

40. M. Nomura, K. Yammota, I. Horie, and K. Fujita, J. Appl. Polym. Sci., 27, 2483 (1982).
41. B. S. Hawkett, D. H. Napper, and R. G. Gilbert, J. Polym. Sci., Polym. Chem. Ed., 19, 3173 (1981).

42. J. Guillot, Acta Polym., 32, 593 (1981).

43. P. Potisk and I. Capek, Angew. Makromol. Chem., 222, 125 (1994).

44. I. Capek, J. Bartoň, and A. Kárpátyová, Makromol. Chem., 188, 703 (1987).

45. J. L. Gardon, J. Polym. Sci., 6, 643 (1968).

46. L. Couture and T. G. M. van de Ven, Colloids Surf., 54, 245 (1991).

47. F. W. Bilmeyer, "Textbook of Polymer Science," 2nd ed., John Wiley and Sons, Inc., New York, N.Y., 1981. 